ISSN 1982-8713

\title{
O que Aconteceu na História da Ciência: A contribuição de Cheikh Anta Diop ${ }^{103}$
}

\section{What happened in the history of science: The contribution of Cheikh Anta Diop}

\author{
Jorge Henrique Almeida de Jesus ${ }^{1}$ \\ ${ }^{1}$ Mestre em História pelo Programa de Pós-Graduação em História da Universidade do Estado do Rio de \\ Janeiro (PPGH-UERJ) com orientação da Profa. Dra. Maria Regina Candido. E-mail: \\ jh.almeidadejesus@gmail.com.
}

Recebido em 30 de julho de 2020; Aceito em 10 de dezembro de 2020

DOI: $10.12957 /$ nearco.2020.57699

\section{Resumo}

A ciência foi considerada monopólio do mundo ocidental por muito tempo. A história da ciência consagrou a ciência clássica e a ciência moderna como os únicos tipos válidos de conhecimento científico. Entretanto, a partir do início do século XX uma série de fatores contribuiu para alterar as perspectivas sobre a origem e o desenvolvimento da ciência. Os historiadores das civilizações não ocidentais, a exemplo de Joseph Needham, especialista em história da China, e Cheikh Anta Diop, especialista em Egito Antigo, contribuíram para o desmonte da perspectiva eurocêntrica da ciência ao fornecerem evidências do conhecimento científico e filosófico fora do Ocidente e antes do Ocidente.

Palavras-chave: História da Ciência; História da Filosofia; Cheikh Anta Diop; Egito Antigo.

\begin{abstract}
Science has long been considered a monopoly of the Western world. The history of science has established classical science and modern science as the only valid types of scientific knowledge. However, from the beginning of the twentieth century, a number of factors contributed to changing perspectives on the origin and development of science. Historians of non-Western civilizations, such as Joseph Needham, an expert on

\footnotetext{
${ }^{103}$ Agradeço ao sinólogo André da Silva Bueno, professor do Departamento de História da Universidade do Estado do Rio de Janeiro (UERJ), por me convidar para participar desta publicação. Sem o seu incentivo este artigo não teria sido redigido.
} 
Chinese history, and Cheikh Anta Diop, an expert on Ancient Egypt, contributed to the dismantling of the Eurocentric perspective on science by providing evidence of scientific and philosophical knowledge outside the West and before the West.

Keywords: History of Science; History of Philosophy; Cheikh Anta Diop; Ancient Egypt.

\section{Introdução}

Os antigos gregos deixaram muitos relatos sobre a excelência alcançada pelos egípcios em vários domínios da ciência. Eles também registraram a dívida intelectual que possuíam com estes últimos. Do século $V$ a.C. o melhor exemplo é a História, escrita por Heródoto de Halicarnasso (485 a.C. - 425 a.C.). Em determinado momento, ao dizer que foram os egípcios os primeiros a ter a ideia de consagrar cada mês e cada dia do mês a uma divindade, assim como pioneiros na predição do futuro de uma pessoa a partir da observação da sua data de nascimento, fez questão de dizer que "os poetas gregos fizeram uso dessa ciência, mas os egípcios tem a primazia neste, como em muitos outros ramos do conhecimento humano" (Heródoto, História, v. 2.83).

Entre os ramos do conhecimento humano no qual os egípcios deteriam a primazia estava a geometria. Ao registrar as informações recebidas dos sacerdotes egípcios a respeito do reinado de Sesóstris - forma pela qual os gregos se referiam a Senusret, nome adotado por três faraós da 12a dinastia, no Médio Império (2052 a.C. 1778 a.C.) -, Heródoto registrou que aquele rei realizou a partilha das terras, concedendo a cada egípcio uma porção igual, com a condição de lhe ser pago todos os anos certo tributo. Caso o rio Nilo carregasse uma porção do lote de determinada pessoa, esta poderia pleitear junto ao soberano o envio de agrimensores ao local, que determinariam a redução sofrida pelo mesmo e ajustariam o valor do tributo a ser pago. "Eis, segundo me parece, a origem da geometria, que teria passado desse país para a Grécia. Quanto ao gnomo, ou relógio solar, e à divisão do dia em 12 partes, os Gregos devem-no aos Babilônios" (Heródoto, História, v. 2.109). 
ISSN 1982-8713

Na Europa do século XIX, Paul Tannery (1843-1904), destacado historiador da matemática, escreveu que só a Grécia antiga produziu ciência de fato. Apenas a matemática helênica era teórica e rigorosa, sendo a matemática de todos os outros povos, incluindo egípcios e babilônios, apenas empírica. A matemática grega se espalhou pelo mundo antigo no período helenístico, mas sofreu uma interrupção bruta após o esfacelamento do Império Romano do Ocidente, de tal sorte que o período medieval representa a mais pesada sombra que jamais se viu desde então na história da ciência europeia. A ciência de forma geral e a matemática de maneira específica renasceram das cinzas a partir da modernidade, especialmente no século XVII. Os árabemuçulmanos, apesar do seu empenho, não deixaram coisas muito grandes para o pensamento científico. O primeiro passo foram os gregos que deram, o segundo e todos os demais foram aos europeus (CHEMLA; PEIFFER, 2001, p. 367-392).

Desde a perspectiva de Heródoto até a de Tannery, representativas da percepção do mundo clássico e do século XIX a respeito da ciência, muita coisa aconteceu. Os povos da África e da Ásia, que antes eram reconhecidos como produtores e difusores do saber, foram substituídos pelo Ocidente, eleito como centro exclusivo da elaboração científica. Afinal, o que aconteceu na história da ciência?

A pergunta anterior já foi posta e respondida por muitos estudiosos antes de nós. Eles disseram que desde o final do século XVIII e, sobretudo, no decorrer do século XIX, considerava-se que o conhecimento evoluía e progredia numa única direção. Ele teria começado na Grécia antiga e sido aperfeiçoado na Europa moderna, livre de qualquer influência dos povos não ocidentais, que sequer teriam conhecido o pensamento racional. A partir do início do século XX, porém, a origem e o desenvolvimento do conhecimento científico foram repensados. Os filósofos e sociólogos da ciência teriam dado contribuições decisivas ao introduzirem noções como as de ruptura epistemológica e revolução científica e ao chamarem a atenção para a influência do meio social sobre a ciência e os cientistas. 
ISSN 1982-8713

Thomas Khun, no livro a Estrutura das revoluções científicas, diz que a pesquisa científica é realizada com base em um paradigma, que orienta e delimita a parcela da realidade a ser investigada. Eventualmente, as pesquisas descobrem fatos ou fenômenos que não podem ser explicados pelo paradigma vigente, comportando-se como anomalias. Estas anomalias, por conseguinte, estimulam os cientistas a formularem novas teorias capazes de explicá-las (KHUN, 1970, p. 131). Defendemos a hipótese de que algo semelhante ocorreu no campo da história da ciência a partir de meados do século XX. Os historiadores das civilizações não europeias, ao identificarem evidências de conhecimentos científicos entre elas, foram levados a formular uma nova teoria sobre a origem e o desenvolvimento do conhecimento científico. Nesta, os fenômenos mencionados são compreendidos como pluricêntricos. É neste sentido que destacaremos a contribuição de Cheikh Anta Diop (1923-1986), filósofo, químico e egiptólogo senegalês que questionou a ideia de que a ciência e a filosofia começaram com os antigos gregos e evoluíram com os europeus. Para ele, havia ciência no Egito antigo, visto como uma civilização negra e africana, assim como uma filosofia, ambas anteriores às gregas. Estas, aliás, teriam se beneficiado com os conhecimentos produzidos por aquelas. Mas antes de analisarmos as ideias deste autor, precisamos fazer uma breve recapitulação sobre o que aconteceu no campo da história da ciência.

\section{Breve história da história da ciência}

A ideia de que a ciência seria um conhecimento especificamente ocidental, portanto desconhecido pelos povos dos outros continentes, assim como a noção de que sua versão moderna teria superado a clássica, possui uma longa história. No século XVI, à época do renascimento cultural, os primeiros praticantes da chamada "ciência moderna" apresentaram duas tendências no que diz respeito aos conhecimentos clássicos. Um grupo considerava que os saberes produzidos pelos gregos e romanos eram valiosos e deveriam ser preservados, atualizados e aprofundados, ao passo que 
outro segmento entendia que as novidades do mundo moderno colocavam problemas e questões desconhecidas pelos antigos, que não poderiam contribuir em nada ou quase nada para a sua resolução no presente. Dever-se-ia partir da observação da realidade e começar do zero.

As duas tendências mencionadas podem ser percebidas quando apreciamos a maneira como os médicos do século XVI encaravam a medicina humoral, de origem greco-romana. De acordo com os princípios e práticas da medicina clássica, a saúde humana dependia do equilíbrio dos quatro humores ou fluidos corporais, que vinham a ser o sangue, o catarro, a bílis amarela e a bílis negra. Esses humores equivaliam aos quatro elementos que compunham o universo, isto é, o ar, a água, o fogo e a terra, os quais possuíam suas qualidades, sendo quente ou frio, seco ou úmido. A variação na qualidade dos humores presentes no organismo gerava as doenças, razão pela qual o tratamento e a cura deveriam fazer uso do método dos contrários, no qual era administrado ao enfermo um remédio com a qualidade inversa à da doença manifestada, visando ao reequilíbrio (ALFONSO-GOLDFARB, 1994, p. 22-23).

Para muitos médicos modernos, a medicina humoral estava correta, devendo ser mantida e praticada conforme prescrito nos textos clássicos. Outros, porém, acreditavam que ela estava ultrapassada e deveria ser descartada como um saber inútil. A figura do período que mais encarnou esta tendência foi Paracelso (1493-1541). Para este, a doença não decorria do desequilíbrio do organismo, mas de uma agressão externa, uma espécie de envenenamento que o corpo não era capaz de combater. Por essa razão, a maneira mais eficaz de tratar e curar o doente seria a aplicação de um antídoto, fornecendo ao corpo as mesmas armas do mal que o combatia. Ao invés do método dos contrários, Paracelso preconizava que iguais curavam iguais (ALFONSOGOLDFARB, 1994, p. 24).

No século XVIII e, principalmente, no decorrer do XIX, a tendência representada por Paracelso ganharia cada vez mais adeptos nos vários ramos da ciência. É que a partir 
ISSN 1982-8713

desse período as ideias de evolução e progresso tomaram conta das mentes dos cientistas. Augusto Comte (1798-1857), na obra Leçons de philosophie positive, formulou uma teoria que influenciaria profundamente a ideia que se faria da ciência desde então. Chamada de positivismo, defende que a humanidade teria passado por três estágios diferentes, sendo o primeiro o teológico, o segundo o metafísico e o terceiro o científico (ou positivo). Não precisamos nem dizer que foram os europeus modernos quem, na ótica de Comte, atingiram o terceiro estágio, o mais evoluído de todos, ao passo que os outros povos se encontrariam ou no primeiro ou no segundo estágios.

Na visão positivista, a ciência moderna é considerada como a melhor forma de compreensão do mundo natural e humano e é usada como parâmetro para a avaliar o nível de conhecimento alcançado pelos outros povos. Assim, o saber da sociedade $\mathrm{x}$ ou y é entendido como mais correto e evoluído quanto mais se aproxime daquele modelo, e mais errado e atrasado quanto mais se afastar dele.

Ao estudar o campo da história da ciência, Ana Maria Alfonso-Goldfarb afirmou que desde o renascimento até o início do século $X X$ a história da ciência foi dependente da ciência moderna e utilizada de acordo com os interesses desta última. Do século XVI ao XVIII, quando a ciência moderna ainda estava se constituindo e precisava se legitimar aos olhos da sociedade, os cientistas praticaram uma narrativa histórica que visava fundamentar e legitimar os interesses do seu modelo de pesquisa científica. No século XIX, por sua vez, quando a ciência já havia se consolidado, a história da ciência tornouse uma mera crônica dos feitos internos da ciência moderna. Em todo esse período a história da ciência demonstrou-se incapaz de fazer uma análise crítica do fazer científico, razão pela qual não fez mais do que ecoar as ideias de ciência formuladas no meio científico. A noção da ciência moderna como um conhecimento cumulativo e progressivo, feito por grandes homens, livre de influências do meio social e como 
exclusividade da Europa moderna não foi submetida à análise crítica e, portanto, difundiu-se para o público leigo como sendo a mais pura verdade dos fatos.

Um bom exemplo da ideia de ciência mencionada anteriormente encontra-se na obra do francês Paul Tannery (1843-1904). Autodidata interessado em ciências humanas e exatas, a partir dos anos 1870 começou a estudar e publicar sobre a história da matemática, apresentando predileção pelas matemáticas grega e bizantina, por um lado, e pela do século XVIII, por outro. Reconhecido por seus contemporâneos como um grande historiador da matemática, sua obra conheceu apreciável difusão nos círculos intelectuais europeus. Ao lado de homens como Moritz Cantor, Gustav Eneström e Gino Loria, trabalhou para transformar a história da matemática em disciplina autônoma e para organizar a disciplina de história da ciência em nível internacional (CHEMLA; PEIFFER, 2001, p. 369-370).

Em artigo para a Revue de synthèse, publicado em 1900, Tannery refletiu sobre as possibilidades de desenvolvimento da história da matemática e mencionou a relevância da teoria positivista para a investigação da trajetória dessa área do conhecimento. Desde que entrou em contato com as ideias de Comte, ele se pôs como objetivo verificar e precisar a validade das mesmas em relação às matemáticas. Manifestou algumas reservas em relação à lei dos três estágios - para ele, seria melhor falar em estágios pré-científico e científico do que em estágio teológico, metafísico e científico -, mas reteve da abordagem de Comte a visão geral, sintética e vulgarizadora da história da ciência, e assim como ele julgava necessário incluí-la nos estudos sobre a história da civilização (CHEMLA; PEIFFER, 2001, p. 371).

No livro Pour l'histoire de la science hellène. De Thalès à Empédocle, publicada em 1887, Tannery defendeu a tese de que a ciência grega não resultou da evolução lenta ou do progresso contínuo do conhecimento; ao contrário, surgiu de forma brusca no século V a.C. Antes da ciência grega, não havia nenhuma outra ciência ou ideia de ciência; depois dela, dois imortais deixaram seu legado, a saber, Hipócrates e 
Aristóteles. Resultado do helenismo, a ciência antiga desapareceu com a queda do Império Romano do Ocidente. No período histórico posterior, isto é, na Idade Média, simplesmente não havia ciência, tal como não havia entre qualquer outro povo fora do Ocidente.

No que tange especificamente à matemática, Tannery distinguiu a matemática empírica ou prática da teórica ou abstrata. A primeira nasceu sob a pressão das necessidades técnicas e artísticas e foi utilizada por todos os povos; este tipo de matemática, acrescentou o autor, não oferecia interesse à história da matemática. Já a segunda, mais elaborada e rigorosa, foi um produto exclusivo do mundo grego, que a transmitiu para a civilização helenística, porém se interrompeu com o advento do período medieval, assim como ocorreu com a ciência antiga de modo geral. Após "quatroze séculos de servidão científica", disse ele, a ciência e, com ela, a matemática, renasce no século XVII (CHEMLA; PEIFFER, 2001, p. 373-374), mais uma vez em solo europeu.

Como se vê, na ótica dos cientistas e historiadores da ciência do século XIX, aqui representados por Tannery, a ciência moderna seria a versão mais acabada, completa, evoluída e progressista do conhecimento científico. A ciência antiga, greco-romano, teria surgido de forma espontânea, livre de qualquer influência estrangeira; o saber teria recuado no período medieval e ressurgido a partir do século XVII no continente europeu. Todos os saberes diferentes passaram a ser avaliados, valorizados e descartados tendo como referência os da ciência moderna. Desse modo, a matemática grega interessava na medida em que teria sido teórica como a do século XVII, mas tudo o que se distanciasse desse padrão deveria ser descartado como sendo desvios da rota certa do conhecimento. Para Comte, esta rota começava no estágio teológico, passava pelo metafísico e conduzia ao positivo. Para Tannery, começava no pré-científico e seguia até o científico. 
NEARCD: Revista Eletrônica de Antiguidade 2020, Volume XII, Número II - ISSN IS82-8713

Núcleo de Estudas da Antiguidade - NEA

Universidade do Estado do Rio de Janeiro

ISSN 1982-8713

A partir da década de 1930 essa visão sofreu profundas modificações. A origem e o desenvolvimento do conhecimento científico foram colocados em outros termos. A própria noção de ciência como um fenômeno exclusivo do mundo ocidental foi posta em xeque. Mas, afinal, como isso deu?

Apontar o momento exato em que ocorrem inflexões no pensamento sempre é uma atividade difícil e arriscada. No entanto, passando a história da ciência em revista, podemos apontar autores e obras que, de forma descontínua, é verdade, desempenharam um papel maior no processo de redirecionamento da perspectiva eurocêntrica da ciência. Segundo Alfonso-Goldfarb, o positivismo acreditava que a boa reflexão histórica deveria evidenciar as etapas do conhecimento humano de forma coerente, isto é, criando uma espécie de modelo dessa transformação ou aprimoramento. Essa pesquisa histórica deveria analisar o maior número de documentos possível a fim de que se compreendesse o verdadeiro processo percorrido pela ciência. Essa tarefa historiográfica revelou-se difícil, produzindo na maioria das vezes crônicas repletas de detalhes pouco inteligíveis, que pouco contribuíam para o esclarecimento da trajetória percorrida pela ciência. Contudo, ao estimular essas pesquisas, a filosofia positivista acabou contribuindo indiretamente para a descoberta e valorização da ciência medieval. O melhor exemplo disso é a obra histórica e filosófica do físico francês Pierre Duhem (1861-1916):

Duhem, um homem de vasta cultura, consegue encontrar e traduzir manuscritos originais antigos e medievais, como fizera Berthelot. Mas seu objetivo com este material é provar uma tese sobre o processo do conhecimento parecida com a de Mach. Só que essa tese tem a preocupação de demonstrar a continuidade nunca interrompida do processo. Com isso, pela primeira vez na História da Ciência, em época moderna, o conhecimento medieval é valorizado. $E$, embora Duhem tenha feito também uma história seletiva do que Ihe parecia ter gerado a ciência moderna (portanto, seu objetivo continua sendo a explicação desta forma de ciência), a dívida da futura História da Ciência para com ele será eterna (ALFONSO-GOLDFARB, 1994, p. 65-66). 
ISSN 1982-8713

Algo novo ocorreu na história da ciência com Duhem. A ciência moderna, que até então havia ignorado e desprezado a diversidade científica, seja no tempo ou no espaço, relegando a segundo plano as ciências das épocas anteriores e dos povos não ocidentais, começou a perceber a existência de outras ciências e reconhecer suas dívidas para com elas. Ao invés de ser única, a ciência moderna seria mais uma dentre várias; ao invés de ponto de partida, seria a continuação da busca do conhecimento iniciada antes dela.

O século XIX iniciou a valorização da diversidade científica no plano temporal - a Idade Média, considerada como a "Idade das Trevas", pela primeira vez tinha sua ciência reconhecida -, mas ainda se estava em solo europeu. Somente a partir do século XX um novo passo foi dado na direção do desmonte da perspectiva eurocêntrica, pois só então as ciências não europeias dos vários períodos históricos começaram a ser reconhecidas. As civilizações da Ásia e da África, cujas ciências foram marginalizadas em diferentes graus, pouco a pouco foram reabilitadas. A entrada em cena de historiadores especializados nestas civilizações levou o debate a um novo patamar, quase invertendo tudo o que se pensou e acreditou até então. A Europa, antes considerada pioneira na produção do conhecimento científico, passou a figurar em determinadas narrativas como o continente onde a ciência se desenvolveu de forma tardia e sob a influência das asiáticas e africanas. Vejamos detalhadamente como isso ocorreu.

Alfonso-Goldfarb identificou as diferentes etapas em que se deu o processo de desconstrução do eurocentrismo e de valorização da diversidade científica pelos historiadores da ciência. De acordo com ela, nas primeiras décadas do século XX predominou a produção de obras monumentais sobre a história da ciência. Tratava-se de coleções de dez ou vinte volumes em que o modelo seguido era o da históriapedrigree - eram lineares, progressivas, acumulavam grande número de datas e nomes importantes. Contudo, algumas delas começaram a se interessar por outros modelos de ciência. Lynn Thorndike (1882-1965), por exemplo, passou trinta anos da sua vida dedicado à elaboração de uma obra monumental em oito volumes. Embora tenha 
NEARCD: Revista Eletrônica de Antiguidade 2020, Volume XII, Número II - ISSN IS82-8713

Núclea de Estudas da Antiguidade - NEA

Universidade do Estado do Rio de Janeiro

ISSN 1982-8713

mantido ideias tradicionais, como a de conhecimento progressivo, inovou ao tematizar a história da magia e da experimentação. Assim, buscou destacar o valor das ciências que não eram necessariamente teóricas e que não tinham a física como modelo. A busca pelos precursores, isto é, os pais da ciência, começava a perder importância com essa narrativa (ALFONSO-GOLDFARB, 1994, p. 75-76).

A valorização de outros modelos de ciência, tal como feito por Thorndike, foi acompanhada por outras atitudes, que geraram consequências mais profundas no processo de renovação da história da ciência. A partir dos anos 1930, os historiadores da ciência começaram a discutir acerca da influência do meio social na rua produção do conhecimento científico. Nascia o externalismo, corrente de pensamento que se opunha ao internalismo, mais preocupado com os problemas internos à ciência, como a evolução dos seus conceitos e teorias, independente da sociedade ou do meio em que eram produzidos. A emergência daquela corrente levou á humanização da figura do cientista. Este, mesmo que brilhante e inspirado, passou a ser encarado como um indivíduo comum, sujeito a vários tipos de pressão e hábitos próprios da sociedade em que estivesse inserido (ALFONSO-GOLDFARB, 1994, p. 76-77).

Além de trabalhos como o de Thorndike e da emergência do externalismo, foi de suma importância para a desconstrução do eurocentrismo e a valorização da diversidade científica a ruptura com a ideia de que o conhecimento científico se desenvolvia de forma continuada, sempre progredindo e se acumulando numa só direção, que seria a direção natural do pensamento humano. Ao invés de manter a ciência moderna como parâmetro de avaliação das outras ciências, que seriam melhores ou piores à proporção que se aproximassem ou afastassem delas, afirmava-se a ideia de considerar cada ciência de acordo com os objetivos fixados por elas mesmas. Iniciava-se um debate sobre a natureza do conhecimento que levaria ao abandono das velhas certezas fornecidas pela história da ciência tradicional (ALFONSO-GOLDFARB, 1994, p. 78-79). 
Os filósofos e sociólogos da ciência participaram ativamente desse debate, introduzindo noções novas, como as de ruptura epistemológica e revolução científica. De diferentes modos, eles defenderam o caráter não linear do conhecimento científico, que se formaria a partir de rupturas e continuidades em relação a conhecimentos anteriores, como defendeu Gaston Bachelard, ou por meio de rupturas profundas - as revoluções científicas -, como teorizou Thomas Khun.

É verdade que a contribuição desses pesquisadores foi fundamental para o novo conceito de ciência, mas o desmonte da perspectiva eurocêntrica não seria possível sem a contribuição dos historiadores das civilizações não europeias. Joseph Needham (19001995) foi um bioquímico britânico interessado em história e filosofia das ciências. Ele participou de um grupo de biólogos marxistas da Universidade de Cambridge que foi fortemente afetado pelas ideias levadas pela delegação soviética ao Segundo Congresso Internacional de História das Ciências, ocorrido em Londres em 1931. Este congresso marcou o início da corrente externalista, segundo a qual a ciência é produzida sob a influência do meio social, tal como mencionamos anteriormente. Se bem que o contato com essa corrente tenha contribuído para alterar a concepção de ciência de Needham, o evento apontado por ele como o mais importante para a transformação da sua vida foi o contato com três estudantes chineses, chegados à Cambridge em 1937. Através deles, Needham conheceu a história da China, apaixonou-se por ela e dedicou-se ao aprendizado do seu idioma, deslocando-se para lá já em 1942. Em sua primeira temporada no país asiático, debruçou-se sobre uma massa documental contendo inúmeras evidências de conhecimentos científicos e técnicos chineses, muitos deles anteriores ao seu surgimento no mundo ocidental. As evidências apontavam que os chineses haviam elaborado inúmeras teorias astronômicas, como aquela referente às manchas solares. Que haviam entendido a origem biológica dos fósseis. Algumas das experiências alquímicas mais antigas da história remontam a 133 a.C. e foram realizadas por chineses. Sabiam que os minerais eram eficazes no tratamento de determinadas doenças, antecedendo neste domínio o famoso Paracelso. De forma pioneira, 
ISSN 1982-8713

defenderam a ideia de que as espécies animais não eram imutáveis, mas que mudavam ao longo do tempo, hipótese que seria defendida por Charles Darwin e Alfred Russel Wallace muito depois, no século XIX. No que diz respeito às técnicas, criaram os barcos movidos a remos, a roda hidráulica, a perfuração de poços profundos, os relógios mecânicos e os taxímetros para medir as distâncias. Criaram também dispositivos mecânicos automatizados, primeiras máquinas cibernéticas. Os chineses também foram os primeiros a conceber a imunização, já que há registros de médicos que retiraram o conteúdo da pústula variolosa e a implantaram na mucosa do nariz, vindo alguns deles a obter a cura (GARZA-ALMANZA, 2016, p. 15-19). Evidências como estas levaram Needham a redigir o clássico Science and civilisation in China, publicado em vários volumes a partir de 1954 (CHEMLA; PEIFFER, 2001, p. 370-371).

Em contraposição à história da ciência tradicional, representada por uma linha do tempo unidirecional, em que a ciência começava na Grécia antiga, estacava na Europa medieval e ressurgia a partir do século XVII no mesmo continente, Needham defendeu a tese de que a ciência havia emergido em diferentes civilizações e épocas. Os conhecimentos científicos produzidos pelos diferentes povos ao longo do tempo confluíram numa mesma direção, o oceano da ciência moderna. Desse modo, ao invés de pensar o século XVII como o momento de uma revolução científica exclusiva do Ocidente, Needham o interpretou como a época da grande síntese dos saberes apropriados por essa parte do mundo. Não por acaso essa síntese ocorreu justamente no momento em que os países europeus haviam se lançado na expansão marítima e ampliado os contatos com a Ásia, a África e a América.

A concepção da ciência moderna como síntese de vários saberes gerou várias consequências. Do ponto de vista epistemológico, pôs em outros termos a ideia que se tinha do processo de formação do saber científico, antes visto como exclusividade do Ocidente e doravante compreendido como resultado de esforços múltiplos. Implicou também na formulação de um novo projeto ético-politico ligado à ciência. Este projeto 
ISSN 1982-8713

pode ser referido a partir da seguinte pergunta: quem tem direito à ciência? Se a ciência é o produto de um esforço coletivo, multiétnico, todos os povos têm direito a participar das pesquisas e dispor dos conhecimentos e produtos tecnológicos dela derivados.

O inventário das ciências chinesas feito por Needham forneceu as evidências concretas de que o conhecimento científico não era monopólio do mundo ocidental. Ele demonstrou que havia ciência fora do Ocidente e antes do Ocidente. Mais, que a ciência não ocidental, no caso a chinesa, contribuiu para a eclosão da ciência moderna. Diante disso, indagamos: que contribuição os historiadores das civilizações africanas deram para a renovação da história da ciência? É o que veremos a seguir através da análise da obra de Cheikh Anta Diop.

\section{"Eu sou a chuva que lança a areia do Saara sobre os automóveis de Roma"}

Os geógrafos dizem que a dinâmica climática deve ser entendida de maneira global, pois um fenômeno de origem local pode surtir efeitos em diferentes partes do planeta. As diferenças de pressão atmosférica geram como respostas os ventos; quanto maior e mais repentina a diferença de pressão atmosférica entre duas áreas, mais força eles terão para se movimentar e carregar consigo partículas presentes no seu ponto de origem. $\mathrm{O}$ ar quente do deserto do Saara, por exemplo, tende a subir e formar uma célula de baixa pressão. De acordo com a direção e velocidade dos ventos, a areia do deserto pode ser levada em grande quantidade para regiões situadas a muitos quilômetros de distância, atingindo países ao norte do Mediterrâneo e mesmo no leste da América.

Ao visitar a Itália, o cantor e compositor Caetano Veloso notou uma poeira enigmática sobre os automóveis de Roma. Ao indagar o que era aquilo, ouviu como resposta que se tratava do Sirocco: areia do Saara ${ }^{104}$. Inspirado no fenômeno climático,

\footnotetext{
${ }^{104} \mathrm{~A}$ areia do Saara atravessa o oceano e atinge outros continentes. Disponível em <http://www.clickideia.com.br/portal/conteudos/c/37/23047>. Acesso: 26/07/2020.
} 
Veloso compôs a canção "Reconvexo". Nela, exprime de forma poética a ideia de que a cultura também deve ser compreendida de forma global. Ideias e práticas iniciadas com um povo por vezes influenciam outras culturas, que as recebem e transformam. A Bahia teria se comportado assim. O recôncavo baiano teria recebido influências externas e a reconvertido de maneira própria, original. É por isso que o eu lírico inicia dizendo, ou melhor, cantando que "Eu sou a chuva que lança a areia do Saara / Sobre os automóveis de Roma / Eu sou a sereia que dança, a destemida lara / Água e folha da Amazônia", remetendo à origem e transmissão da cultura, para concluir descartando "Quem não é recôncavo e nem pode ser reconvexo" ${ }^{105}$.

Para Cheikh Anta Diop, a origem e desenvolvimento do conhecimento científico e filosófico também devem ser entendidos como fenômenos globais. Ele surgiu no Egito antigo e, tal como a areia do Saara, foi lançado sobre as mentes dos filósofos das póleis gregas. Estes as reconverteram em ideias próprias e, por sua vez, as retransmitiram para outros povos e épocas. Essas concepções e práticas viajaram no espaço e no tempo, chegando à Europa medieval, à África pré-colonial e ao mundo árabe-muçulmano.

Em Civilisation ou barbarie: anthropologie sans complaisance, publicado em 1981, Diop retomou e aprofundou a história do conhecimento que vinha desenvolvendo desde a década de 1950. Nele, procurou demonstrar a existência dos conhecimentos científicos egípcios, sobretudo no que se refere às ciências matemáticas, naturais e aplicadas, remontando à segunda metade do quinto milênio antes da nossa era; a existência de uma filosofia faraônica, atestada em papiros desde o terceiro milênio daquela era; a anterioridade e influência exercida pela ciência e filosofia egípcias sobre suas equivalentes gregas, formadas a partir de meados do primeiro milênio antes da era cristã; a transformação desses conhecimentos pelos gregos; e a difusão ou reintrodução dos mesmos na África pré-colonial.

\footnotetext{
${ }^{105}$ A canção "Reconvexo" foi composta por Caetano Veloso e gravada por Maria Bethânia no álbum “Memória da Pele", de 1989.
} 
ISSN 1982-8713

Segundo Diop, uma ciência rigorosa, dotada de teoria e método, portanto não empírica, estava presente no Egito desde a segunda metade do $V$ milênio antes da nossa era. Esta afirmação é válida para as ciências aplicadas e, mais precisamente, para a astronomia. Os antigos egípcios criaram e utilizaram de forma simultânea diversos tipos de calendário, entre os quais o civil, o sideral e o litúrgico. No civil, o tempo era contado da seguinte maneira: o ano foi dividido em 365 dias, sendo 12 meses de 30 dias, perfazendo o total de 360, mais 5 dias epagômenos, cada um destes consagrado a um deus do panteão egípcio. Eles sabiam que essa divisão não correspondia integralmente a uma revolução sideral completa, que ocorre a cada 365 dias e $1 / 4$ e, diante disso, fizeram uma escolha reveladora do grau de conhecimento astronômico que detinham. Ao invés de optarem pelo ano bissexto, que consiste em acrescentar um dia a cada quatro anos (retificando assim o 1/4 não computado no ano de 365 dias), os egípcios preferiram acompanhar esse atraso durante 1.460 anos e só então retificá-lo. Ocorre que o período de 1.460 anos é exatamente o intervalo de tempo que separa duas ascensões helíacas de Sirius, fenômeno natural em que a referida estrela aparece juntamente com o Sol na latitude de Mênfis. Isso demonstra que além do calendário civil, baseado em uma cronologia relativa, os egípcios também faziam uso do sideral, pois usavam aquele fenômeno natural, o nascimento helíaco de Sirius, como referência temporal (DIOP, 1981, p. 353-358).

A longa periodicidade do evento é a principal evidência de que sua utilização como base do calendário não decorreu da simples observação - teria sido necessário observá-lo ao menos duas vezes para deduzi-lo, o que custaria 2.920 anos! Assim, considerando que foi registrado um nascimento helíaco em 139 a. C. e que, por dedução, os anteriores ocorreram em 1.318-1321 a.C., 2.778-2781 a.C. e 4.238-4.241 a.C., e sabendo que um tumba de Abidos de 3.330 a.C. contém registro de uma saudação à Sirius, referida como a estrela que inaugura o novo ano e fornece a inundação, Diop concluiu que o calendário sideral já estava em uso antes desta última data. Havia, 
portanto, não apenas conhecimento empírico, mas uma ciência astronômica no Egito antigo datando de pelo menos 4.236 a.C.

Além das ciências aplicadas, as ciências exatas estavam presentes no Egito desde pelo menos a primeira metade do terceiro milênio antes de Cristo. Entre os egípcios havia astrônomos e também matemáticos. Dentre os vários ramos da matemática analisados por Diop, entre os quais constam a geometria, a trigonometria, a álgebra e a aritmética, mencionemos à título exemplificativo os dois primeiros, a geometria e trigonometria.

Segundo Diop, o Papiro de Moscou, o Papiro Rhind e o Papiro de Kahun permitem afirmar que os egípcios conheciam as fórmulas exatas das superfícies e volumes de várias figuras geométricas. Eles sabiam, por exemplo, a fórmula da superfície da semiesfera, a saber, $S=2 \pi R^{2}$, e por conseguinte conheciam a da esfera, $S=4 \pi R^{2}$; conheciam o teorema relativo ao volume do tronco da pirâmide, $V=\frac{1}{3} h\left(a^{2}+a b+\right.$ $\left.b^{2}\right)$; conheciam a fórmula do volume da pirâmide, $V=\frac{1}{3} a^{2} h$; conheciam há milênios o teorema do quadrado da diagonal, atribuído a Pitágoras, de acordo com o qual, num triângulo retângulo, o quadrado da hipotenusa é igual a soma dos quadrados dos catetos; conheciam o problema da quadratura do círculo, tendo sido os primeiros, na história da matemática, a colocá-lo em questão e resolvê-lo; sabiam calcular corretamente a inclinação da pirâmide a partir das linhas trigonométricas habituais (seno, cosseno, tangente ou cotangente); conheciam a fórmula da superfície do círculo, $S=\pi R^{2}$; e também a da superfície do retângulo, $S=L \times l$; assim como da superfície do triângulo, $S=\frac{1}{2} a h$; e a do trapézio, $S=\frac{A+B}{2} \times h$; bem como as fórmulas do volume do cilindro, do paralelepípedo e da esfera. O Papiro de Kahun indica que, possivelmente, também sabiam calcular o volume do cilindro.

Os exemplos mencionados anteriormente não esgotam os conhecimentos matemáticos egípcios, mas dão uma noção precisa do nível alcançado por elas. Diop não 
NEARCD: Revista Eletrônica de Antiguidade 2020, Volume XII, Número II - ISSN IS882-8713

Núcleo de Estudas da Antiguidade - NEA

Universidade do Estado do Rio de Janeiro

ISSN 1982-8713

foi o primeiro a estudar as matemáticas faraônicas; antes dele, desde os anos 1930 historiadores da matemática já vinham se dando conta de que antes dos gregos e fora da Grécia já seria possível falar em matemática teórica, e não apenas empírica. Vasily Vasilievitch Struve, que editou o Papiro de Moscou, foi um dos pioneiros na renovação das perspectivas sobre a história da matemática egípcia. Contudo, essa visão inovadora ainda permaneceria sob dúvida por muitas décadas. Em livro da década de 1950, escrito por Serge Sauneron, um dos grandes expoentes da egiptologia, ainda lemos que as matemáticas egípcias seriam empíricas e não teóricas ${ }^{106}$. Apoiando-se na corrente historiográfica inovadora, aqui representada por Struve, Diop procurou reforçá-la por meio da análise da documentação textual grega. Ele afirmou que os gregos que viajaram e estudaram no Egito foram unânimes em afirmar o valor das matemáticas egípcias, o que reforça a tese de que elas eram teóricas e rigorosas.

Além de criarem e desenvolverem um conhecimento científico, os antigos egípcios produziram um saber filosófico no sentido estrito do termo. Partindo do princípio de que a filosofia é um conhecimento caracterizado pela separação entre mito e conceito e pela autoconsciência enquanto pensamento, o egiptólogo em questão procurou analisar os papiros escritos desde a segunda metade do III milênio a.C., portanto, desde o Antigo Império (2780 a.C. - 2280 a.C.), e verificar se as cosmogonias hermopolitana, heliopolitana, menfita e tebana podiam ser consideradas como filosofia.

De acordo com as referidas cosmogonias, o universo e tudo o que ele contém não surgiu do nada - ex nihilo nihil fit, como diriam milênios depois os latinos. No princípio de tudo estava o nun, matéria primordial incriada, caótica, sem começo nem

\footnotetext{
${ }^{106}$ Ele escreveu o seguinte: "En revanche les quelques papyrus dits "mathématiques" qui sont parvenus jusqu'à nous font plus figure de recueils de recettes pour résoudre tel ou tel problème d'arithmétique ou de géometrie simple que de manuels attestant la connaissance de règles de résolution: au milieu de tous les cas de problèmes dont ils traitent, l'empirisme et l'approximation règnent em maîtres. Tout laisse croire que les connaissances de calcul et de géométrie, à en juger par ses documents, se limitaient aux cas pratiques devant lesquels pouvait se trouver um scribe ou un architecte. La géométrie théorique semble absente de leurs préoccupations", SAUNERON, Serge. Les prêtres de l'ancienne Égypte. Paris: Éditions du Seuil, 1957, p. 155.
} 
fim, mas contendo em estado potencial todos os seres e coisas. Em determinado momento, por ação do deus Kheper, princípio do movimento, o deus Rá toma consciência de si mesmo e da existência do universo. Assumindo a função de demiurgo, este deus completa a criação do mundo sensível, principiando pela geração dos primeiros oito deuses do panteão egípcio (a ogdóade). Os dois primeiros casais de deuses, Shu e Tefnut, Geb e Nut, encarnam o ar e a água, a terra e o fogo, os quatro elementos que por oposição irão dar forma ao mundo sensível. Rá, que emergiu do nun e pôs-se a completar a criação dos seres e coisas que já existiam em estado potencial nas águas abissais primordiais, fez uso da palavra para chamar os seres à existência. $O$ próprio ser humano, que é introduzido no mundo por meio da relação entre Osíris e Ísis, contém em sua composição parte da energia do cosmo, o $K a$ universal. Do ponto de vista ontológico, o ser humano partilha de uma energia com os demais seres vivos e com o universo circundante. Insere-se o princípio da imortalidade da alma.

Os sistemas de pensamento egípcios eram a um só tempo materialista e idealista. Materialista porque na origem do universo estava o nun, matéria sem começo nem fim, contendo em estado latente tudo o que viria a existir e contendo também o princípio da transformação capaz de transformar o possível no real, o latente no existente. O próprio Kheper, princípio do movimento, e Rá, demiurgo, não são apontados como anteriores ou causadores do nun, mas como seres que emergiram deste. Contudo, além desse componente materialista, os sistemas de pensamento egípcio introduziram um componente idealista, pois após a tomada de consciência de si e do mundo por Rá, é este quem, por meio da palavra, completa a criação do mundo sensível, iniciando pela criação dos deuses que, por sua vez, deram origem aos demais seres, incluindo os humanos.

As ideias presentes na cosmogonia egípcia fornecem uma explicação racional sobre a origem do universo, sua estrutura e transformação. São também, portanto, uma cosmologia. Ao postular a anterioridade do nun, os filósofos egípcios lançaram as bases 
ISSN 1982-8713

da corrente materialista; ao postularem o papel demiúrgico de Rá (ou Toth, a depender da cidade egípcia), introduziram os fundamentos do idealismo; ao considerarem que o universo se estruturava a partir da oposição entre os quatro elementos, introduziram a teoria dos contrários; ao conceberem a palavra de Rá como um dos métodos da organização do mundo sensível, introduziram a noção de logos, razão universal; igualmente, ao considerarem que haveria um $K a$ universal vinculado ao $k a$ de cada indivíduo, criaram uma ontologia. Havia, portanto, uma filosofia egípcia desde pelo menos o III milênio a.C.

Mas o que dizem os historiadores da filosofia tradicionais? Sejamos curiosos e abramos um livro de filosofia. Em um deles, intitulado Convite à filosofia, escrito por Marilena Chauí, nos deparamos com a seguinte afirmação: “Os historiadores da filosofia dizem que ela possui data e local de nascimento: fim do século VII a.C. e início do século VI a.C., nas colônias gregas da Ásia Menor, na cidade de Mileto. E o primeiro filósofo foi Tales de Mileto" (CHAUÍ, 2000, p. 28). No mesmo livro, lemos que a filosofia grega possui quatro períodos, sendo o primeiro o pré-socrático, ou cosmológico, o segundo o socrático, o terceiro o sistemático e o último o helenístico, ou greco-romano. O primeiro é o que mais no interesse no momento, por se tratar do início da filosofia helênica. Ele começou no final do século VII a.C. e se estendeu até o limite do século $V$ a.C., desenvolvendo-se inicialmente nas cidades da Jônia, localizada na Ásia Menor, da Magna Grécia, situada no sul da Itália e Sicília e, também, na cidade de Abdera, encravada na Trácia.

A principal preocupação dos filósofos desse período, prossegue a autora, era a origem do mundo e as causas das transformações da natureza. A cosmologia em questão não admite que o mundo tenha sido criado a partir do nada, e sim que haveria um princípio natural de onde tudo vem e para onde tudo retorna. Esse princípio é a physis, que é a causa natural contínua e imperecível da existência de todos os seres e de suas transformações. A physis, por sua vez, é definida como a natureza tomada em sua 
NEARCD: Revista Eletrônica de Antiguidade 2020, Volume XII, Número II - ISSN IS882-8713

Núcleo de Estudas da Antiguidade - NEA

Universidade do Estado do Rio de Janeiro

ISSN 1982-8713

totalidade, entendida como princípio e causa primordial da existência e das transformações das coisas naturais, o que inclui os seres humanos, e compreendida como o conjunto ordenado e organizado de todos os seres naturais ou físicos. A physis é imortal, mas as coisas físicas são mortais. O caráter mortal e mutável das coisas geradas pela physis é expressa por outro conceito, o de kínesis, que pressupõe que o universo está em perpétua transformação. A ideia de movimento das coisas e do mundo também está na raiz de outro conceito, o de devinir. Por fim, a autora destaca que, embora todos os pré-socráticos afirmassem as ideias anteriormente referidas, eles possuíam diferentes entendimentos sobre o que era a physis. Ela escreveu:

\footnotetext{
Cada filósofo encontrou motivos e razões para determinar qual era o princípio eterno e imutável que está na origem da natureza e de suas transformações. Assim, Tales dizia que a physis era a água ou o úmido; Anaximandro considerava que era o ilimitado, sem qualidades definidas; Anaxímenes, que era o ar ou o frio; Pitágoras julgava que era o número (entendido como estrutura e relação proporcional entre os elementos que compõem as coisas); Heráclito afirmou que era o fogo; Empédocles, que eram quatro raízes (úmido, seco, quente e frio); Anaxágoras, que eram sementes que contêm os elementos de todas as coisas; Leucipo e Demócrito disseram que eram os átomos (CHAUÍ, 2000, p. 41-42).
}

Como se vê, a história da filosofia tradicional limita temporal e espacialmente o surgimento desta ao século VII a.C. no território grego, mas não se dá conta de que o referido pensamento apresenta conexões com outro, no caso o egípcio, que lhe é anterior e que, por conseguinte, não deveria ter sido alojado no exterior do campo filosófico. Por que a filosofia teria começado com os gregos do primeiro milênio antes da nossa era se sua cosmologia, que por meio do conceito de physis afirma que o mundo não começou do nada, foi precedida pela ideia egípcia de que o nun sempre existiu e conteve em estado potencial todas as coisas e seres? Por que dizer que ela começou com os filósofos pré-socráticos que, através dos conceitos de kínesis e devenir, disseram que o mundo está em perpétua transformação, se os antigos egípcios, desde o terceiro milênio daquela era, já haviam colocado a ideia de que Kheper era o princípio da transformação, responsável por fazer a passagem do estado potencial ao real? Por que fazer de Tales de Mileto o primeiro filósofo da história da humanidade quando sabemos 
NEARCD: Revista Eletrônica de Antiguidade 2020, Volume XII, Número II - ISSN IS882-8713

Núcleo de Estudas da Antiguidade - NEA

Universidade do Estado do Rio de Janeiro

ISSN 1982-8713

que este, que considerava a physis como a água ou o úmido, foi antecedido pelas cosmogonias/cosmologias heliopolitana, hermopolitana, menfita e tebana que já haviam colocado a ideia dos quatro elementos primordiais?

Para Diop, a ideia de que a filosofia começou com os gregos no período citado acarreta vários problemas. Ela não apenas desconsidera a existência de filosofias diferentes e anteriores a grega, como cria um obstáculo à correta compreensão da gênese desta filosofia. Partindo do princípio de que havia filosofia no Egito desde o terceiro milênio a.C. e de que esta foi fundamental para a eclosão de sua equivalente grega, Diop lançou mão da "história comparada da filosofia", em que procurou demonstrar que muitas ideias consideradas originalmente gregas tiveram sua origem entre os egípcios. Entre os vários argumentos usados para sustentar essa hipótese, gostaríamos de destacar um. Considerando que há um parentesco cultural unindo Egito antigo e África negra, ele procurou identificar elementos comuns às cosmogonias egípcias e dos demais povos negro-africanos para demonstrar que determinadas noções consideradas anteriormente como exclusivas da filosofia grega foram criadas no mundo africano. Ele notou, por exemplo, que as cosmogonias dos egípcios, dos bambaras e dos dogons possuem uma concepção numérica do mundo similar e que reaparece no pitagorismo e no platonismo. Ele escreveu:

\begin{abstract}
A onipotência do Número é incontestável tanto nos sistemas bambara e dogon como no pitagorismo, onde os dez primeiros números eram dotados de propriedades secretas comparáveis àquelas que lhes atribuem os bambaras. O esforço de abstração que conduz a representar os quatro elementos constitutivos do universo da cosmogonia dogon e heliopolitana por números evoca, curiosamente, as especulações de Platão em Timeu [...]. Nós constataremos que para os dogons e bambaras, [...] o universo é "um número que se move" no sentido literal, rigoroso, platônico do termo (DIOP, 1981, p. 400).
\end{abstract}

As semelhanças entre as cosmogonias africanas e as dos filósofos gregos não são consideradas como casuais, fortuitas, mas como resultado da influência egípcia sobre estes. Os gregos, sobretudos os da Ásia Menor, estabeleceram contatos diretos e indiretos com a civilização egípcia, particularmente no primeiro milênio antes da nossa era, quando as relações comerciais e culturais entre ambos se intensificaram. Além disso, é sabido que muitos filósofos gregos viveram e estudaram no Egito, entrando em contato direto com as ideias filosóficas 
NEARCD: Revista Eletrônica de Antiguidade 2020, Volume XII, Número II - ISSN IS882-8713

Núcleo de Estudas da Antiguidade - NEA

Universidade do Estado do Rio de Janeiro

ISSN 1982-8713

elaboradas em cidades como Heliópolis, Hermópolis, Mênfis e Tebas. Baseado em Diógenes Laércio, autor clássico que escreveu sobre a vida de Pitágoras, Diop afirmou que esses estudantes gregos conheciam a língua egípcia e era por meio desta que adquiriam os conhecimentos egípcios. Diante disso, chamou a atenção para a existência de palavras egípcias na língua grega. Se o Egito e a África negra pertencem ao mesmo universo cultural, suas línguas também são aparentadas. Logo, nada mais natural do que encontrar palavras comuns às línguas egípcia e negro-africanas na língua grega. No capítulo "Vocabulário grego de origem negroafricana" ele fornece uma lista de palavras comuns ao egípcio antigo e ao wolof e que se encontra no grego. Numa atitude ousada, pôs em questão até mesmo a origem do vocábulo physis, cujo significado literal é "o que se tornou". Segundo ele, "até mesmo a origem dessa palavra pode ser negro-africana e egípcia". Reparou, en passant, que a palavra fes, em wolof, significa devenir, aparecer, visível, por oposição ao oculto (DIOP, 1981, p. 447).

Contudo, não devemos ver Diop como um defensor do difusionismo unidirecional, no qual um povo elabora um fenômeno cultural e outro se limita a recebê-lo passivamente. Ao contrário, ele considera que a filosofia grega é resultado não de uma simples continuação, mas de uma ruptura epistemológica em relação a sua equivalente egípcia. O conceito de ruptura epistemológica foi formulado por Gaston Bachelard e pressupõe a ideia de que o conhecimento não é cumulativo e evolutivo, mas forjado a partir da continuidade e descontinuidade em relação a saberes anteriores ${ }^{107}$. Seguindo essa orientação, Diop defende que os gregos, após absorverem as ideias egípcias, souberam transformá-las. Enquanto no Egito a corrente de pensamento idealista coexistiu com a materialista, na Grécia surgiram escolas filosóficas exclusivamente materialistas, introduzindo uma ruptura radical na maneira de apreender a realidade. Ele escreveu:

Se considerarmos a escola idealista grega (Platão, Aristóteles e os estoicos), nenhuma diferença essencial aparece em relação ao Egito, já que se trata de um pensamento egípcio modificado: em toda a cosmogonia platônica e na metafísica aristotélica o mito coabita pacificamente com o conceito. Platão poderia até mesmo ser chamado, à justo título, de Platão, o mitólogo. Mas as coisas mudam radicalmente com a escola materialista grega; os princípios, as leis de evolução da natureza tornam-se propriedades intrínsecas da matéria,

${ }^{107}$ Gaston Bachelard foi professor e orientador de Diop na Sorbonne, em Paris, entre os anos 1940 e 1950. 
NEARCD: Revista Eletrônica de Antiguidade 2020, Volume XII, Número II - ISSN IS82-8713

Núcleo de Estudas da Antiguidade - NEA

Universidade do Estado do Rio de Janeiro

ISSN 1982-8713

que já não precisam mais ser duplicadas, mesmo simbolicamente, em divindades, bastando-se a si mesmas. Da mesma forma, toda causa primordial de natureza divina é rejeitada; o mundo não foi criado por nenhuma divindade, a matéria sempre existiu. Por mais que esse pensamento seja o desenvolvimento lógico do componente materialista da cosmogonia egípcia, ele se separou suficientemente do seu modelo para se tornar propriamente grego; o materialismo ateu é uma criação puramente grega, o Egito e a África negra parecem tê-lo ignorado. Quanto às condições sóciopolíticas de seu nascimento, isto já é uma outra história (DIOP, 1981, p. 412).

Outra diferença fundamental entre a filosofia egípcia e a grega diz respeito ao método de transmissão do saber. Os egípcios, ao longo de toda a sua história, mantiveram-se fieis ao método da transmissão do saber pela iniciação, fazendo dele o monopólio de um grupo social específico, alheio às demais camadas sociais. Os gregos, ao contrário, romperam com essa instituição e fizeram do saber um conhecimento público, coletivo. O sistema iniciático, aliás, foi uma característica partilhada pelo Egito e os demais povos da África negra e foi considerado pelo autor como um dos principais obstáculos epistemológicos para a ciência e filosofia africanas de modo geral. "Mas a tradição iniciática africana degrada os pensamentos quase científicos que ela recebeu em épocas muito antigas ao invés de enriquecê-las com o tempo" (DIOP, 1981, p. 405).

A história da ciência e da filosofia escritas por Diop gerou forte reação nos campos da egiptologia, dos estudos clássicos e dos estudos africanos. Alguns estudiosos rejeitam-nas totalmente, outros parcialmente, e ainda outros as aceitam de maneira integral. A respeito dos dois primeiros grupos, remeto o leitor para o livro Afrocentrismes. L' Histoire des Africains entre Égypte et Amérique, ao passo que para o terceiro, indico o periódico Ankh-Revue d'égyptologie et des civilisations africaines, principal veículo de comunicação da Escola Africana de Egiptologia, que segue o paradigma diopiano.

Para ilustrar a questão das críticas, mencionemos ao menos um exemplo do primeiro grupo - o dos que rejeitam totalmente. Segunda Mary Lefkowitz, sob o pretexto de combater a narrativa eurocêntrica da história da antiguidade, Diop teria invertido os termos e escrito uma história afrocêntrica, que assim como a primeira seria caracterizada pelo etnocentrismo. Enquanto antes as culturas ocidentais estavam situadas hierarquicamente acima das demais, na historiografia diopiana são as culturas africanas, a começar pelo Egito, que são localizadas no 
NEARCD: Revista Eletrônica de Antiguidade 2020, Volume XII, Número II - ISSN IS82-8713

Núcleo de Estudas da Antiguidade - NEA

Universidade do Estado do Rio de Janeiro

ISSN 1982-8713

centro da história. Assim, a civilização grega seria destituída de sua originalidade e entendida como um mero receptáculo das influencias faraônicas.

Ao contrário do que sustentou Diop, a autora defende que "a filosofia propriamente dita parece ser uma invenção puramente grega". Ainda que os filósofos gregos tenham ido ao Egito para estudar com os sacerdotes deste país, "eles não teriam aprendido nada em matéria de filosofia". No que diz respeito à Platão, mesmo que seja possível que ele tenha ido ao país dos faraós, "nada indica na sua obra, tal como nos chegou, que ele tenha aprendido qualquer coisa a respeito do Egito que não possa ter aprendido lendo Heródoto" (LEFKOWITZ, 2000, p. 240241).

Para Lefkowitz, portanto, a poeira que Caetano Veloso viu sobre os automóveis de Roma não seria areia do Saara. Seria areia de alguma praia do norte do Mediterrâneo.

\section{Conclusão}

Do século XVI até o começo do XX, os cientistas e historiadores da ciência apresentaram algumas ideias em comum. Além de partilharam a mesma ideia de verdade científica - vista como correspondência entre ideia e coisa-, confluíram no sentido de fazer da ciência moderna o único ou o melhor modelo de conhecimento científico. Assim, para eles, a ciência seria um fenômeno exclusivo do mundo ocidental, fosse ele antigo ou moderno, enquanto outros, ainda mais restritivos, alegaram que ela era exclusiva da Europa moderna. Este grupo, ao desconsiderar até mesmo as ciências pré-modernas europeias, como a medieval, certamente votaram total desprezo às ciências dos povos não europeus, como os africanos e asiáticos. Povos como os antigos egípcios ou os chineses não teriam conhecido a ciência, mas tão-somente a "sabedoria". Esta, ao contrário daquela, não seria dotada de teoria, sendo puramente empírica.

Na primeira metade do século XX, porém, os filósofos, sociólogos e historiadores da ciência, além dos próprios cientistas, começaram a abandonar a concepção de verdade definida anteriormente. Ao redefinirem a verdade científica como uma coerência interna entre as coisas, lançaram as bases da concepção construtivista, que segue sendo até hoje a predominante. Os construtivistas também romperam com outras ideias de ciência, como, por exemplo, a visão do 
NEARCD: Revista Eletrônica de Antiguidade 2020, Volume XII, Número II - ISSN IS82-8713

Núcleo de Estudas da Antiguidade - NEA

Universidade do Estado do Rio de Janeiro

ISSN 1982-8713

conhecimento científico como cumulativo, linear e progressivo, bem como com a concepção eurocêntrica que dava à Europa antiga e/ou moderna acesso exclusivo à ciência.

A renovação da história da ciência não se deu apenas a partir das contribuições dos filósofos, sociólogos e historiadores da ciência, mas também por meio da contribuição dos historiadores das civilizações não europeias. Assim foi que vimos Joseph Needham realizar o inventário dos conhecimentos científicos chineses, desenvolvidos muitas vezes antes e independentemente da ciência moderna, e apontar a contribuição destes conhecimentos para o surgimento e desenvolvimento da ciência na Europa a partir do século XVII.

Analogamente ao feito por Needham em relação à China, Diop fez o levantamento dos conhecimentos científicos e filosóficos africanos, desde a antiguidade egípcia até o período précolonial, e demonstrou que não apenas havia ciência e filosofia na África, como estes conhecimentos foram cruciais para o surgimento da ciência e filosofia na Grécia antiga que, por sua vez, transformou e retransmitiu muitos desses conhecimentos para a ciência moderna.

$\mathrm{Na}$ antiguidade concebia-se o saber como produto coletivo (foi o que Heródoto nos disse). Na modernidade ele passou a ser percebido como propriedade de uma civilização, a ocidental. No século XX, como quem volta atrás para pegar algo que ficou caído no caminho, ressurgiu a ideia do saber científico como resultado do esforço do conjunto da humanidade. Eis, em linhas gerais, o que aconteceu na história da ciência.

\section{Referências bibliográficas}

\section{Documentação}

HERÓDOTO. História. Volume I. Tradução: J. Brito Broca. Estudo crítico: Vítor de Azevedo. Rio de Janeiro: Nova Fronteira, 2019.

\section{Bibliografia}

ANKH - REVUE D'EGYPTOLOGIE ET DES CIVILISATIONS AFRICAINES. Gif-sur-Yvette : Khepera, 1992. № 1. ISSN 1164-6136.

ALFONSO-GOLDFARB, Ana Maria. O que é história da ciência. São Paulo: Brasiliense, 1984. 
NEARCD: Revista Eletrônica de Antiguidade 2020, Volume XII, Número II - ISSN IS882-8713

Núcleo de Estudas da Antiguidade - NEA

Universidade do Estado do Rio de Janeiro

ISSN 1982-8713

BACHERLARD, Gaston. La formation de l'esprit scientifique: contribution à une psychanalyse de la connaissance objective. Paris: Librairie philosophique J. Vrin, 1967.

BUENO, André da Silva. O extremo Oriente na antiguidade. Rio de Janeiro: Fundação CECIERJ, 2012.

CHAUÍ, Marilena. Convite à filosofia. São Paulo: Ática, 2000.

CHEMLA, Karine; PEIFFER, Jeanne. Paul Tannery et Joseph Needham deux plaidoyers pour une histoire générale des sciences. Revue de synthèse: 4e sér., nos 2-3-4, avr.-déc. 2001, p. 367392.

DIOP, Cheikh Anta. Civilisation ou barbarie: anthropologie sans complaisance. Paris: Présence Africaine, 1981.

DIOP, Cheikh Anta. L'Afrique noire précoloniale: étude comparée des systèmes politiques et sociaux de l'Europe et de l'Afrique Noire, de l'Antiquité à la formation des États modernes. Paris: Présence Africaine, 1987.

DIOP, Cheikh Anta. Nations nègres et culture. De l'antiquité nègre égyptienne aux problèmes culturels de l'Afrique Noire d'aujourd'hui. Paris: Présence Africaine, 1990.

DIOP, Cheikh Anta. Antériorité des civilisations nègres - Mythe ou verité historique? Paris: Présence Africaine, 1993.

DIOP, Cheikh M'Backé. Cheikh Anta Diop: I'homme et l'oeuvre. Paris: Présence Africaine, 2003. GARZA-ALMANZA, Victoriano. Joseph Needham y la Ciencia de la Antigua China. CULCyT//MayoAgosto, 2016, Año 13, No 59, p. 15-19.

JESUS, Jorge Henrique Almeida de. Olhar o Egito e ver a África: das reminiscências modernas do Egito negro à Escola Africana de Egiptologia (1787 a 2001). 2019. 134 f. Dissertação (Mestrado) - Universidade do Estado do Rio de Janeiro. Rio de Janeiro, 2019.

KHUN, Thomas S. A estrutura das revoluções científicas. Tradução: Beatriz Vianna Boeira e Nelson Boeira. São Paulo: Perspectiva, 1970.

LEFKOWITZ, Mary. Le monde antique vu par les afrocentristes. In: FAUVELLE-AYMAR, FrançoisXavier ; CRHÉTIEN, Jean-Pierre ; PÉRROT, Claude Hélène (org.). Afrocentrismes. L' Histoire des Africains entre Égypte et Amérique. Paris: Karthala, 2000.

MAZRUI, Ali A.; AJAYI, J.F. Ade; BOAHEN, A. Adu; TSHIBANGU, Tshishiku. Tendências da filosofia e da ciência na África. In: MAZRUI, Ali A.; WONDJI, Christophe (orgs.). História Geral da África. Volume VIII: África desde 1935. Brasília: UNESCO, 2010. 
NEARCD: Revista Eletrônica de Antiguidade 2020, Volume XII, Número II - ISSN IS82-8713

Núcleo de Estudas da Antiguidade - NEA

Universidade do Estado do Rio de Janeiro

ISSN 1982-8713

MODERNA, Elis. O surgimento da ciência/filosofia moderna e a construção de uma concepção utilitarista de natureza. Revista Geografia em Atos, no 15, vol. 1, p. 1-14.

SAUNERON, Serge. Les prêtres de l’ancienne Égypte. Paris: Éditions du Seuil, 1957.

VIDEIRA, Antonio Augusto Passos. Historiografia e história da ciência. Revista Escritos, Ano 1, no 1, 2007, p. 111-158. 